\title{
Erratum to: Editorial 41
}

\section{Eric Scerri}

\section{Erratum to: Found Chem (2012) 14:107 DOI 10.1007/s10698-012-9157-x}

To the reader of issue Found Chem (2012) 14(2):107: due to a miscommunication, the introduction mentions an article by Professor Sima that is not included in this issue, and fails to introduce the article of Professor Martins. Foundations of Chemistry apologises for any confusion to the reader.

The online version of the original article can be found under doi:10.1007/s10698-012-9157-x.

E. Scerri $(\bowtie)$

Department of Chemistry and Biochemistry, UCLA, Los Angeles, CA 90095, USA

e-mail: scerri@chem.ucla.edu 